Acta Hispanica (2018) 23: 135-145

\title{
LA CUESTIÓN CATALANA EN LA SEGUNDA REPÚBLICA
}

\section{Anita Zalai}

\author{
Universidad de Szeged
}

\begin{abstract}
Resumen: A base de informes diplomáticos húngaros, el artículo intenta analizar la cuestión de la autonomía catalana que fue uno de los desafíos para resolver para los políticos de la segunda república española. En principio, todos los partidos republicanos aceptaron el derecho de las naciones menores a la autonomía, pero en cuanto a su contenido ya eran divididos. Para Manuel Azaña la cuestión de la autonomía no era un tema legal, sino un medio para resolver una cuestión política muy importante. Pero hubo posiciones muy diferentes dentro de la coalición gubernamental, que iban desde partidarios de la unidad hasta posiciones federalistas. Aún más, las fuerzas políticas catalanas también eran divididas. El Estatuto catalán, adoptado en septiembre de 1932, fue una solución de compromiso resultado de una dura lucha. En consecuencia, los nacionalistas catalanes tenían que estar satisfechos con el estado de una región autónoma dentro del estado español en lugar del estado autónomo catalán. Sin embargo, la lucha continuó entre el gobierno central y el gobierno catalán. El artículo intenta hacer ver cómo percibieron los diplomáticos húngaros este conflicto tan complejo.
\end{abstract}

Palabras clave: Segunda República, Azaña, Maciá, Estatuto catalán, Companys

\begin{abstract}
Based on Hungarian diplomatic reports, the article attempts to analyze the issue of Catalan autonomy which was one of the challenges to be solved by the politicians of the Second Spanish Republic. In principle, all the republican parties accepted the right of minor minorities to autonomy, but in terms of their/its content they were divided. For Manuel Azaña the issue of autonomy was not a legal issue, but a means to resolve a very important political issue. But there were very different positions within the coalition government, ranging from supporters of the unity to federalist positions. Further more, the Catalan political forces were also divided. The Catalan Statute, adopted in September 1932, was a compromise resulting from a hard struggle. Consequently, the Catalan nationalists had to be satisfied with an autonomous region within the Spanish state instead of the autonomous Catalan state. However, the struggle continued between the central government and the Catalan government. The article tries to show how Hungarian diplomats perceived this complex conflict.
\end{abstract}

Keywords: Second Spanish Republic, Azaña, Maciá, Catalan Statute, Companys

La Segunda República española fue proclamada el 14 de abril de 1931, dos días después de las elecciones concejales del 12 de abril. Después de siete años de la dictadura de Miguel Primo de Rivera fue la primera vez que convocaron elecciones en el país. Según los resultados, en las ciudades grandes los partidos republi- 
canos obtuvieron la mayor cantidad de votos. Primero, en Eibar, en un pueblo del País Vasco fue proclamada la república a las seis de la mañana, y como las noticias se difuendieron rápido, hubo una tensión enorme en las otras ciudades también. En Madrid, a las tres de la tarde izaron la bandera republicana en el Palacio de Correos en la Plaza de Cibeles. Sin embargo, en Barcelona se precipitan los acontecimientos. A la una y cuarenta, Luis Companys, el líder de la Esquerra Catalana, proclamó la república en el balcón del ayuntamiento e izó la bandera tricolor de la república. Una media hora más tarde, Francesc Maciá, la figura principal del nacionalismo catalán-por radio, en lengua catalana-ya proclamó la República Autónoma de Cataluña "como parte integrante de la Confederación Ibérica". Estos acontecimientos ya indicaron las tendencias en el nacionalismo catalán.

La ambición de independencia del Coronel Maciá era un problema serio para el Gobierno Provisional de la Segunda República. Finalmente, los represenantantes del gobierno pudieron llegar a un acuerdo con el líder catalán. En las negociaciones de intermediario jugó un papel importante Luis Companys. Companys, que fue el segundo líder catalán después de Macia, consideró que la autonomía era más importante que lograr la independencia total. Por lo tanto, el gobierno republicano central encontró un aliado perfecto en él (Zalai, 2011:65).

El tema regional fue uno de los temas clave del programa de reforma de la coalición gubernamental, coalición republicano-socialista, que se formó después de las elecciones a cortes constituyentes de junio de 1931. En principio, todos los partidos republicanos aceptaron el derecho de las naciones menores a la autonomía, pero en cuanto a su contenido ya eran divididos. Para Manuel Azaña, primer ministro del gobierno y político de un partido de la izquierda burguesa, la cuestión de la autonomía no era un tema legal, sino un medio para resolver una cuestión política muy importante. Pero hubo posiciones muy diferentes dentro de la coalición gubernamental sobre el tema regional, que iban desde partidarios de la unidad hasta posiciones federalistas (Zalai, 2011:186-187).

Pál Hevesy, el embajador húngaro en Madrid, visitó a Alejandro Lerroux, ministro español de asuntos exteriores, el 24 de abril de 1931, para informarle sobre el reconocimiento del gobierno provisional español por parte de Hungría. El mismo día informó al ministro de asuntos exteriores húngaro, al conde Gyula Károlyi sobre la conversación con el ministro español y la experiencia de las dos primeras semanas de la República. Hevesy destacó el problema regional, con sus 
palabras el "desafío del separatismo" como el problema más grave tan solo dos semanas después de la proclamación de la República. Así escribió sobre esto:

\begin{abstract}
Hay un movimiento fuerte en varias provincias para separarse de Madrid. Lo justifican por el hecho de que solo quieren pagar tanto impuesto, que corresponde a las necesidades de su propia provincia. No entienden, dicen los separatistas, ¿por qué contribuir a los gastos centrales cuando ya no hay ninguna corte real, no hay más colonias y lo que hay casi no importa y el Marruecos Español casi no tiene valor/, ¿para qué necesitan un gran ejército, ¿para qué necesitan la flota, muchas escuelas de cadetes. Su seguridad externa no está en peligro por nadie. Como imperio, perdieron todo lo que se había podido perder, ahora simplemente quieren tener una buena administración y quieren tener en cuenta sus otros intereses de escala limitada.[...] En mi opinión -dice el diplomático húngaro- hay intereses comunes que de momento no van a llegar hasta una separación completa, sin embargo, sin duda eso es una nueva situación en este país porque la corona, el enlace de conexión y el símbolo de las grandes tradiciones ha caído de la cabeza del Rey Alfonso. ${ }^{1}$
\end{abstract}

El debate sobre el tema de la autonomía fue muy lento en el parlamento. El borrador del Estatuto catalán se discutió al mismo tiempo que la Reforma Agraria, desde mayo de 1932. En su discurso parlamentario del 27 de mayo, Manuel Azaña -gran orador del parlamento de la Segunda República- tratando el tema del proyecto de autonomía catalana no lo calificó de una concesión a los catalanes, sino como una consecuencia lógica del nuevo sistema político español. Su discurso de tres horas impresionó no solo a sus propios partidarios, sino también a la oposición, y los catalanes estaban contentos. A pesar de eso, el debate parlamentario siguió muy lento (Zalai, 2011:161).

El Estatuto catalán, adoptado en septiembre de 1932, fue una solución de compromiso resultado de una dura lucha. Los nacionalistas catalanes tenían que estar satisfechos con el estado de una región autónoma dentro del estado español en lugar del estado autónomo catalán. La mayoría de los políticos españoles -apretando los dientes- abandonaron el ideal del estado centralizado. El diplomático húngaro subrayó "la tenacidad y habilidad gubernamental de Azaña" que contribuyó a poder votar el programa. También añadió que, finalmente, aceleró

${ }^{1}$ Magyar Országos Levéltár (Archivo Nacional Húngaro) MOL, K63, 273. csomó, 29/1. tétel, 25/pol./ 1931 
las negociaciones del estatuto catalán, que ya se habían estancado, la conspiración del 10 de agosto, que acercó a los partidos republicanos y promovió resolver los conflictos. (El 10 de agosto de 1932 hubo un intento de pronunciamiento militar fracasado en Sevilla con la dirección del general Sanjurjo.) El intento de pronunciamineto provocó un ambiente revolucionario y Manuel Azaña lo aprovechó para poder votar el estatuto y la ley agraria a la vez.

La introducción de la autonomía catalana también fue bastante difícil. La transferencia de las tareas administrativas referidas a la competencia de la Generalitat fue muy lenta. En su informe del 20 de septiembre de 1932 un encargado de negocios interino de la embajada de Madrid (que sustituyó a Pál Hevesy y cuyo nombre es ilegible en el documento) escribe lo siguiente:

[...] desde el principio se esperaba la votación del proyecto. Obviamente, sin el apoyo de los separatistas catalanes y del Partido Socialista, la República nunca habría nacido. La autonomía y la reforma agraria, por lo tanto, significaban una obligación política que ningún gobierno de la República habría podido rechazar. ${ }^{2}$

En cuanto al contenido del estatuto así escribe:

La propuesta, presentada sobre la base del plebiscito original catalán, solo se ha cortado en un punto sustancial: en el caso de la Universidad de Barcelona. Los catalanes querían una universidad puramente de lengua catalana, y los intelectuales republicanos (Unamuno, Ortega y Gasset) querían proporcionar la primacía del idioma español en las universidades. La solución bilingüe es el compromiso de Azaña.

Además, destaca que "la parte financiera es, sin embargo, bastante beneficiosa para Cataluña". Durante las negociaciones parlamentarias parecía que la restricción mencionada, especialmente la universidad, conduciría a una nueva agitación separatista entre los catalanes. Esta impresión, sin embargo, desapareció después de que se había votado la ley, por lo cual -escribe el diplomático- "toda Cataluña está ansiosa por celebrar el estatuto legal". Para fortalecer "la fraternidad hispanocatalana, Azaña viaja a Barcelona el día 24 de este mes (septiembre - A. Z.) para

2 MOL, K63, 273. csomó, 29/1. tétel, 54/pol./ 1932 A katalán statútum - 1932. szeptember 20. (El estatuto catalán - 20 de septiembre de 1932) 
encontrarse con Maciá. Las visitas van acompañadas de festividades nacionales". Señalando la importancia del estatuto, el diplomático así opina:

no se puede negar que la solución de la cuestión catalana, que los gobiernos reales han intentado sin éxito durante décadas, es políticamente el mayor éxito del gobierno republicano, que ha dado un gran paso adelante para consolidar el nuevo régimen.

El informe analiza detalladamente el contenido jurídico del estatuto y lo resume de la manera siguiente:

desde el punto de vista legal, se puede afirmar que la unidad y la soberanía del Estado se conservan en los puntos esenciales (asuntos exteriores, guerra, reformas sociales, aplicación de la ley), pero también se respetan en gran medida las aspiraciones catalanas.

Además, hace comparación con la situación de la monarquía austro-húngara diciendo que

aun cuando la autonomía no alcanza todas las libertades otorgadas a las nacionalidades en ciertas partes de la monarquía austrohúngara, por ejemplo, el grado de la autonomía croata (el comando croata) representa una solución mucho más progresiva y liberal que los asentamientos minoritarios de los dictados de paz.

Llama la atención de su ministro de asuntos exteriores, Lajos Walkó sobre que "este aspecto del estatuto catalán tiene un importante valor propagandístico que, en mi humilde opinión puede ser explotado en una acción internacional por las libertades de las minorías".

Tras la adopción del Estatuto, en Cataluña se celebraron las elecciones parlamentarias en noviembre de 1932. La Esquerra -el partido representante de la izquierda radical catalana- logró una victoria abrumadora después de obtener más de la mitad de los votos. Así ganó un papel hegemónico entre los partidos catalanes. El segundo partido catalán más importante fue la Lliga Regionalista de las derechas liderado por Francesc Cambo, que también mejoró significativamente su posición en 1932 (Zalai, 2011:169-170). En contraste de las elecciones catalanas, un año más tarde, en las elecciones parlamentarias generales de noviembre de 1933, la derecha llegó al poder, e inmediatamente comenzaron una política antiautónoma (Zalai, 2011:187). 
La mayoría del gobierno de coalición de centroderecha, que estaba en el poder desde 1933, estaba compuesto por fuerzas políticas centralistas. Se oponían a la autonomía provincial y estaban equipados con todos los medios para frenar los procesos en la dirección de la autonomía. La política del gobierno de Madrid provocó grandes tensiones en Cataluña y en el País Vasco y contribuyó a la radicalización del nacionalismo (Zalai, 2011:209).

Según la opinión del conde István Csáky, el nuevo encargado de negocios interino de la embajada de Madrid, lo más curioso de las elecciones concejales de Cataluña de febrero de 1934 fue -a diferencia de las elecciones nacionales de noviembre de 1933 que ganó la derecha- que en Cataluña la izquierda volvió a ganar una mayoría relativa. El diplomático húngaro lo atribuye a dos razones. Por un lado, a la parcialidad del gobierno catalán de izquierda y, por otro lado, le parecía que para los catalanes la cuestión de la autonomía y la política izquierdista seguían siendo inseparables. Y éste -en su opinión- "fue aprovechado por los políticos españoles de la izquierda". Por lo tanto, Cataluña llegó a ser la última bastión del radicalismo izquierdista en España, no tan convencido, como quizás debido al apego a las tradiciones antiguas. ${ }^{3}$

El 1 de marzo de 1934 Csáky informó sobre su conversación con Luis Companys, el jefe de la Generalitat. El diplomático tenía una opinión muy negativa del político catalán diciendo que

$$
\begin{aligned}
& \text { no tiene prestigio entre la población, y si la conciencia catalana } \\
& \text { no fuera tan fuerte en un círculo intelectual reducido pero } \\
& \text { influyente, la desintegración latente después de la muerte de } \\
& \text { Maciá sería aún más llamativa. Los intelectuales antes } \\
& \text { mencionados incluyen muchos oficiales militares de alto rango. }
\end{aligned}
$$

Según la conclusión de Csáky el destino de Cataluña no se determinó con la autonomía. Estaba de acuerdo con Companys que la fuerza de la izquierda todavía estaba centrada en Cataluña por el momento, sin embargo añadió que Companys no se dio cuenta de que eso no era "una concepción política o una cosmovisión, sino solo una complicación con el sentimiento nacional".

3 MOL, K63, 273. csomó, 29/1. tétel, 6/pol./ 1934 Katalán községi választások. Katalónia szerepe a spanyol belpolitikában (Elecciones concejales. El papel de Cataluña en la política interior española)

${ }^{4}$ MOL, K63, 273. csomó, 29/1. tétel, 10/pol./ 1934 Beszélgetés a katalán önkormányzat fejével. 1934. március 1. (Conversación con el dirigente de la autonomía catalana) 
El conflicto catalán se hizo cada vez más grave durante el año de 1934. El gobierno catalán de centro-izquierda creado en enero de 1934 como resultado de las elecciones municipales era una espina en los ojos del gobierno centralista de centro-derecha en Madrid que obstaculizó que expandieran su política a Cataluña. Además, después de la muerte del líder Maciá, el nacionalismo catalán giró a la izquierda. En consecuencia, la Lliga, que representó las fuerzas burguesas de derecha abandonó el Parlamento catalán. Mientras tanto, la transferencia de las competencias a las fuerzas de la autonomía regional avanzaba muy lento.

La tensión aumentó aún más cuando el 12 de abril de 1934 el Parlamento catalán aprobó la Ley de Contratos de Cultivo que dio la posibilidad a los inquilinos de las parcelas que pudieran alquilar las parcelas durante seis años seguidos como mínimo, o después de 18 años de cultivo continuo pudieran comprar las parcelas. La Lliga representando los intereses de los propietarios protestantes acudió a las Cortes de Madrid. En la Tribunal Constitucional la ley fue declarada inconstitucional y declarada nula. En respuesta, los diputados de la Esquerra abandonaron las Cortes, y los diputados del Partido Nacionalista Vasco siguieron su ejemplo como muestra de solidaridad. La tensión entre el gobierno de Madrid y la Generalitat catalana siguió aumentandó cuando el 12 de junio el Parlamento catalán volvió a votar la ley sin ningún cambio. El gobierno de Madrid trató de resolver el problema negociando. Pero, antes de la apertura de la sesión de otoño del parlamento por una serie de eventos se produjo un giro drástico en la política interna española (Zalai, 2011:210-211).

Sin embargo, la cuestión agraria solo fue un pretexto para que la tensión se explotara. Según la opinión de Csáky, "la derecha española nunca había aceptado la idea de la autonomía catalana con sinceridad". Además, las intrigas de la Lliga catalana agravaron la situación aún más. Según la impresión del diplomático húngaro los catalanes de derecha y el resto de España querían desmantelar la autonomía. Como motivos de esta actitud Csáky mencionó que los catalanes acomodados se fueron arruinando por "la legislación social" y entre españoles el apego a las tradiciones era muy fuerte. Sobre la mentalidad catalana así opinó: "Según mis informaciones, esta gente dura puede, en la medida extrema, ir a la resistencia contra España. Y entonces los españoles se rendirán., ${ }^{5}$

\footnotetext{
${ }^{5}$ MOL, K63, 273. csomó, 29/1. tétel, 22/pol./ A spanyol-katalán viszály (El conflicto español-catalán)1934. május 14.
} 
En el informe de 30 de junio de 1934 Csáky analizó la actitud del gobierno de Madrid en cuanto a la cuestión catalana:

el gobierno español quiere ganar tiempo y solo el día 25 (de junio) tomó una posición firme y anuló la ley agraria catalana y prohibió su aplicación. Entre los partidos solo los monárquicos quieren resolver la cuestión catalana con la fuerza del poder para preservar la unidad de España. El comportamiento indeciso de los demás partidos parlamentarios fue uno de los motivos de la resistencia catalana. $^{6}$

Según el informe de 30 de junio de Csáky la mayor parte de la armadura local estaba en manos de los partidarios de Esquerra pero el punto débil de la Generalitat era que los trabajadores, los anarquistas y los sindicalistas estaban desinteresados porque consideraban que los trabajadores no tenían nada que ver con las luchas de la burguesía.

No se puede saber -escribe el diplomático- por el carácter imprevisible de los españoles que un malentendido catalán qué podría desencadenar en todo el país, además, los catalanes no están unidos. Cerca de 700000 residentes españoles no seguirían las instrucciones de Companys.

Sobre las consecuencias económicas así escribe:

Una parte considerable de la industria catalana está en manos españolas, pero en la gran mayoría es catalana. Algunos de los españoles ya habían mudado sus empresas a territorio español [...] En la economía mundial de hoy, sin embargo, esto sería un duro golpe para Cataluña con una gran industria, pero con un área de consumo pequeña. La unión económica es otra causa seria por la que los catalanes no irán a la final.

Al fin, el diplomático húngaro así resume la situación:

Nunca compartí la opinión de quienes habían estado anunciando durante años que la cuestión catalana había sido resuelta por el gobierno de Azaña. No está resuelto. No se puede considerar que el

${ }^{6}$ MOL, K63, 273. csomó, 29/1. tétel 29/pol. A katalán kérdés (La cuestión catalana) 1934. június 30. 
estancamiento sea una solución. Los conflictos raciales, lingüísticos y actitud a la vida realmente separan a los dos pueblos.

El verano de 1934 el problema del regionalismo llegó a ser uno de los problemas más graves para el gobierno central. Para demostrar la gravedad de la situación, Csáky cuenta un incidente interesante en su informe de 26 de agosto ${ }^{7}$ :

Incluso ocurrió la cosa increible que el presidente de la Generalitat catalana, Companys fue a Francia y respondió a la cálida bienvenida de las autoridades francesas expresando su esperanza de que Cataluña se una con Francia en el futuro previsible.

El gobierno silenció el incidente.

Según la opinión del diplomático húngaro "los españoles temen, pero con razón, que puedan dividir su país casi inadvertido pero planificado" como "el regionalismo o si queremos el problema de las razas en España no está resuelto ni económica ni políticamente". ${ }^{8}$

Durante 1934, la tendencia de la polarización de las fuerzas políticas se observó en España. Un acontecimiento decisivo en la vida de la autonomía catalana y en la del propio régimen republicano fue la sublevación de octubre de 1934. El levantamiento finalmente estalló el 5 de octubre, luego de que el primer ministro Lerroux permitiera a Gil Robles ocupar cuatro carteras ministeriales para la CEDA, el gran partido de la derecha, en su nuevo gobierno. En Barcelona, la revolución liderada por Luis Companys no consiguió el apoyo de la CNT, el gran sindicato anarcosindicalista (Zalai, 2011:212).

El encargado de negocios Csáky dio noticias detalladas sobre la revolución el 20 de octubre. En su informe calificó la revolución y la huelga general de 5 de octubre tan traumática como la caída de la Monarquía. "El movimiento empezó en Cataluña donde Companys, el presidente de la Generalitat proclamó la república catalana independiente y pidió al ejército estacionado en Cataluña que se uniera a él."

7 MOL, K63, 273. csomó, 29/1. tétel, 42/pol A regionalizmus problémája Spanyolországban (El problema del regionalismo en España) 1934. augusztus 26.

${ }^{8}$ MOL, K63, 273. csomó, 29/1. tétel, 44/pol Regionalizmus a baszk tartományokban (Regionalismo en las provincias vascas) 1934. szeptember 21. 
En su análisis Csáky subraya que el general Batet -el comandante de la División de Barcelona- era catalán y él con otros oficiales de alto rango, solo después de algunas vacilaciones obedecieron al comando del gobierno central, luego la rebelión catalana fue aplastada después de unas horas de lucha. El objetivo de la revolución -según Csáky- fue "la eliminación del orden actual, pero luego ya anarquistas, comunistas, socialdemócratas y nacionalistas tenían planes diferentes". Al fin añadió: "no creo que esta sea la última revolución en España". Según la opinión del diplomático la causa del fracaso de la revolución fue, por un lado, que la resistencia catalana fue sobreestimada, y por otro lado, debido al colapso de la revolución catalana, el movimiento no comenzó al mismo tiempo en todo el país."

En varios informes suyos Csáky ya reiteraba su opinión que "la mayoría de los catalanes no quiere la guerra o el separatismo", y según él "es por eso y por el comportamiento del general Batet que la rebelión catalana se ha derrumbado como un castillo de naipes". ${ }^{10}$

En Cataluña, la autonomía se suspendió y se introdujo el gobierno militar provisional. En el debate sobre el futuro del Estatuto catalán en las Cortes, los monárquicos exigieron la abolición definitiva de la autonomía, pero la Lliga catalana exigió restablecerla inmediatamente. Finalmente, el gobierno decidió suspender la autonomía por un período indefinido, y las competencias delegadas anteriormente se delegaron en el gobierno central.

Sobre las consecuencias de la rebelión catalana informó con más detalles el 10 de enero de 1936 en el informe político resumido del año $1935 .{ }^{11}$

Según la Ley de 2 de enero de 1935, el Parlamento catalán y la organización autónoma catalana fueron suspendidos [...] El 11 de febrero, el Consejo de Ministros decidió designar un comité para revisar las competencias concedidas a la Generalidad bajo el estatuto catalán. Los

9 MOL, K63, 273. csomó, 29/1. tétel, 51/pol Melléklete: m. kir. Honvédelmi Minisztérium Katonai Főcsoport Főnökének 47/K. Bizalmas! A spanyol forradalom (Confidencial. La revolución española) 1934. október 20.

${ }^{10}$ MOL, K63, 273. csomó, 29/1. tétel,54/K. Batet tábornok szerepe a lázadás leverésében (El papel del general Batet en el aplastamiento de la rebelión) 1934. november 19. 11 MOL, K63, 273. csomó, 29/1. tétel, 1/pol Összefoglaló politikai jelentés Spanyolországról 1935. évre (Informe político sobre España del año 1935) 1936. január 10. 
Anita Zalai

derechos administrativos provistos por el estatuto, con la excepción de los casos de seguridad pública, fueron devueltos a Generalidad antes de fin de año [...] El Consejo de Ministros del 12 de abril decidió que Generalidad podría recuperar sus derechos legales $[\ldots]$

El 27 de mayo, Madrid comenzará el juicio contra el ex presidente de Generalidad, Companys y otros, que finaliza el 31 de marzo. Según la sentencia, los acusados serán condenados a 30 años de prisión y pérdida [...] El 27 de septiembre, el gobierno central abolirá el estado de guerra durante un año en Barcelona [...] 11 de noviembre - Decreto sobre la restauración parcial del gobierno local de Cataluña.

La suerte del Estatuto tras el aplastamiento del golpe intentado por la izquierda catalanista y sus colaboradores, resulta una cuestión de gran interés para calibrar la actitud de la derecha y el centro español ante la cuestión autonómica. El Partido Radical, con el apoyo prácticamente exclusivo de la Lliga, intentará salir de la crisis mediante una suspensión a plazo de la vida de la Generalidad y una recuperación por el gobierno central de las competencias de orden público. La tesis se resume en la idea de que no se ha sublevado la Generalidad, mucho menos todavía Cataluña, sino los dirigentes de izquierda que controlaban las instituciones en la coyuntura de octubre de 1934. Esta actitud resultará marcadamente insuficiente para una derecha "revolucionaria" dispuesta a aprovechar el momento para poner punto final a la autonomía catalana. La CEDA optó por una difícil posición intermedia de discutible constitucionalidad: suspensión indefinida de la normalidad estatuaria con devolución gradual de competencias a la Generalidad (Ayer, 208).

\section{Bibliografía:}

Archivo Nacional Húngaro (MOL)

de Blas Guerrero, Andrés. 1995. "La cuestión nacional y autonómica" Juliá, Santos (ed.). Ayer, 20. Madrid: Marcial Pons. 193-213.

Zalai, Anita. 2011. Politikai pártok Spanyolországban 1931-1936. Szeged: Belvedere Meridionale. 